\title{
On the comprehensive indicator of the effectiveness of programs in the field of environmental safety and environmental development
}

\author{
Anatoly Rybakov ${ }^{1, *}$, Evgeniy Ivanov $^{1}$, Alexander Kuzmin ${ }^{2}$, and Larisa Gorina ${ }^{3}$ \\ ${ }^{1}$ Scientific Research Center, Civil Defense Academy, Khimki, Russia \\ ${ }^{2}$ Kazan National Research Technical University named after A. N. Tupolev - KAI, Kazan, Russia \\ ${ }^{3}$ Togliatti State University, Zhigulevsk, Russia
}

\begin{abstract}
The paper offers a comprehensive indicator for evaluating the effectiveness of the implementation of state policy in the field of environmental safety and environmental development. The indicator under consideration can be a flexible tool for justifying the effectiveness of strategic planning measures in the field of environmental development, taking into account current development trends. The idea of solving the optimization problem (bringing the values of the complex indicator to the maximum) of forming a rational action plan for the implementation of state policy in the field of environmental safety and environmental development is proposed.
\end{abstract}

\section{Introduction}

The events of the beginning of the XXI century forced the world community to come to an awareness of the problems associated with ensuring sustainable development not only of countries, regions, but also of the entire planet as a whole. It is worth noting that the solution of sustainable development issues is on the global agenda. It is worth noting that the documents of international law [1-3] in this area are being developed quite intensively.

The fact that the most attention is paid to environmental issues in the documents under consideration indicates the awareness at the intergovernmental level of the fact that our planet is a very vulnerable to changes (both internal and external) closed system, the preservation of the balance of which is possible only through the systematic implementation of a number of interrelated programs $[4,5]$.

At the same time, mechanisms that allow for a reliable assessment of the effectiveness of the implemented set of measures in the field of environmental safety are not fully developed in detail $[6,7]$.

\footnotetext{
* Corresponding author: anatoll rubakov@mail.ru
} 


\section{Materials and methods}

Our country is no exception, from the point of view of awareness of the issues of ensuring environmental safety and environmental development (including for the long term until 2030 [8]), in particular, it is currently envisaged to solve 13 main tasks in this area. It should be noted that the proposed structure of the Strategy is systematic, since for each task there are from 3 to 12 mechanisms for implementing the provisions of the Strategy. As a disadvantage, it should be noted that there are no indicators for evaluating the effectiveness of the implementation of activities carried out within the framework of the Strategy.

The key idea of the work is to present an approach to determining a comprehensive indicator for evaluating the effectiveness of the implementation of state policy in the field of environmental safety and environmental development.

At the same time, the idea of considering a number of private criteria that characterize private indicators for each of the tasks of environmental development is proposed (1):

$$
P_{i}=1 / k \sum_{k=1}^{n} c_{i}^{k},
$$

where $\mathrm{P}_{\mathrm{i}}$ - is a complex efficiency indicator for the $\mathrm{i}$-th environmental development task; $i$ is the number of the environmental development task (13 tasks in total); $\mathrm{c}_{\mathrm{i}}^{\mathrm{k}}-$ is a particular efficiency indicator for the k-th event of the i-th environmental development task; $\mathrm{k}$ is the number of the implemented event (from 3 to 12, depending on the task).

At the same time, in order to move to dimensionless values of partial indicators for each task, the normalization operation is performed [9] by the following transformation:

$$
\begin{aligned}
& c^{k}{ }_{i}=\frac{c_{i}-c_{\text {crit }}}{c_{\text {targ }}-c_{\text {crit }}} \\
& c^{k}{ }_{i}=\frac{c_{\text {crit }}-c_{i}}{c_{\text {crit }}-c_{\text {targ }}}
\end{aligned}
$$

where $c_{i}$ - absolute values of the measured indicator; $c_{\text {targ }}$ - target values of the measured indicator; $c_{\text {crit }}-$ critical values of the measured indicator.

As follows from the meaning of the normalization operation, expression (2) is used for cases when the purpose of the implemented measures is to increase the absolute values of the indicator, otherwise expression (3) is used.

For the transition to a single complex indicator for evaluating the effectiveness of the implemented environmental development policy, it is possible to combine the $i$-th number of complex indicators of the effectiveness of environmental development tasks in the form of a multiplicative convolution [10].

$$
P_{\Sigma}=\sum_{i=1}^{13} P_{i} a_{i}
$$

where $\mathrm{P}_{\Sigma}-\mathrm{a}$ comprehensive indicator for evaluating the effectiveness of the implemented environmental development policy; $a_{i}-$ is a weighting factor for the $i$-th task of environmental development.

In turn, the weighting coefficients can be found by interviewing the appropriate group of competent experts and processing the results of the survey using the hierarchy analysis method [11]. 


\section{Results and discussion}

Thus, the proposed indicator for evaluating the effectiveness of the implemented environmental development policy will allow for a comprehensive assessment of the current state of the environmental situation, and when tracking the dynamics of changes in the indicator, evaluate the effectiveness of the implemented measures.

At the same time, efficiency will be taken as the value of the increment of the values of the complex indicator, relative to the financial resources allocated within the framework of environmental programs (5).

$$
E=\Delta P_{\Sigma} / M_{\Sigma}
$$

where $\mathrm{E}$ - is an indicator of the effectiveness of the implemented environmental development policy; $\Delta \mathrm{P}_{\Sigma}$ - is the difference between the values of the integrated indicator for evaluating the effectiveness of the implemented environmental development policy for the reporting period (1 year); $\mathrm{M}_{\Sigma}$ - financial resources allocated within the framework of environmental programs.

The presented indicator is a tool for carrying out an ongoing assessment of the state of affairs, which allows assessing the degree of implementation of the provisions of strategic planning documents in the field of environmental safety. However, the assessment should not be an end in itself, for the decision-making manager, forecasting the situation and planning measures to correct it will be of greater interest. In particular, the definition of such measures can be carried out by establishing relationships between the volume of their implementation and the change in the indicator (5) [12-14].

The obtained complex indicator of the effectiveness of the implemented environmental development policy (4) allows us to form a tool for justifying the state policy in the field of rational planning of measures. At the same time, the optimization problem itself looks like this (6):

$$
P_{\Sigma}=f\left(c_{i}, M_{j}, a_{i}\right) \rightarrow \max
$$

where $\mathrm{M}_{\mathrm{j}}$ - financial resources allocated within the framework of the implementation of the $\mathrm{j}$-th event of the $\mathrm{i}$-th environmental development task.

In other words, it is necessary to define such an action plan in the field of environmental safety and environmental development, which will allow achieving the maximum values of the integrated indicator for evaluating the effectiveness of the implemented environmental safety and environmental development policy.

At the same time, the allocated resources should not exceed the total amount of allocated allocations for the implementation of state policy measures in the area under consideration (the maximum and minimum volumes of measures should also be fixed so that the optimization task does not degenerate).

\section{Conclusion}

The paper proposes an approach to the formation of a rational action plan for the implementation of state policy in the field of environmental safety and environmental development, based on the solution of the optimization problem.

This task has some difficulty in establishing a "feedback" between the activities performed and the values of the efficiency indicator, for which a regression analysis method can be recommended, due to the complex structure of the system of environmental safety and environmental development measures, or big data technology. 
Bringing to the maximum of the target function (a complex indicator of the effectiveness of the implementation of state policy in the field of environmental safety and environmental development) can be carried out through the use of gradient methods (5), which consist in a step-by-step search for the largest values of the target function, subject to restrictions on the maximum of financial resources and the permissible limits of variable private indicators.

\section{References}

1. Website of the United Nations, https://www.unisdr.org/

2. Protocol on Strategic Environmental Assessment to the Convention on Environmental Impact Assessment in a Transboundary Context, Website the United Nations, https://www.un.org/

3. Framework Convention on Climate Change. The Paris Convention, Website of the United Nations, https://unfccc.int/

A. V. Kukushkina, Int. legal aspects of environmental safety at the present stage, 218 (2020)

4. D. D. Melnikov, S. D. Zaburdin and E. G. Rakovskaya, The Newman in Foreign policy, 52(96), 1, 49 (2020)

5. Utepbergenov, M. Daumenov, B. Nizamatdinov and et al., Paideuma, 7, 45 (2021)

6. B. Khrustalev and et al., IOP Conf. Ser.: Mater. Sci. Eng. (2019), 471092005

7. Fundamentals of the state policy in the field of environmental development of Russia for the period up to 2030, https://base.garant.ru/

8. E. V. Klyushnikova and E. M. Shitova, Innocenter, 1, 4 (2016)

9. V. I. Borisov, "Ways to improve the effectiveness of modern scientific research," in the Int. Scientific and Practical Conf. (Ufa, 2019), 78

10. V. A. Titov and I. G. Khairulin. Basic research, 10, 2020 (2013)

A. V. Yandritskaya, The paradigm, 1, 17 (2019)

11. N. A. Istomina, National interests: priorities and security, 37(178), 26 (2012)

A. N. Biryukova and O. I. Glushchenko, Bulletin of the Perm University, 2, 24 (2011) 